\title{
The National Referral Database: An initial overview
}

Pre-print article published on: 12/01/2019 doi: $10.31236 /$ osf.io/rgywq

Research conducted by the ukactive Research Institute

Citation: Steele, J., Wade, M., Polley, M., Copeland, R. J., Stokes, S., \& Mann, S. (2019, January 12). The National Referral Database: An initial overview. https://doi.org/10.31236/osf.io/rgywq 


\section{SUMMARY OF KEY FINDINGS}

- In 2014 the National Institute for Health and Care Excellence (NICE) made the recommendation that a system to collate local data on exercise referral schemes should be implemented for evaluation and to inform future practice.

- Exercise referral schemes were first introduced in the 1990s in primary care settings to facilitate exercise participation in those with chronic disease who were inactive.

- The evidence base regarding exercise referral schemes is currently limited and there is still the need for the earlier recommendation from NICE to be met.

- The National Referral Database is a newly formed resource produced in collaboration by ukactive, the National Centre for Sport and Exercise Medicine in Sheffield, and ReferAll, which includes data on a variety of outcomes for patients both pre and post their ERS participation.

- In this report we introduce The National Referral Database, and highlight its potential to facilitate large scale evaluation of exercise referral schemes, and wider social prescribing pathways relating to physical activity. Two accompanying manuscripts present the first findings from analysis of the current data.

- We also introduce plans for future development and expansion of the database. In line with the recent NHS Long Term Plan, the current preventative agenda in healthcare, and a focus on the potential of social prescribing models to facilitate this, we will look to widen the database to include these alternative pathways.

- There are important implications of the introduction of this resource, and its continued development, with respect to; enhancing our understanding of the effectiveness and implementation of these schemes; aiding stakeholders in decision making with respect to strategic policy and commissioning; and for developing standards and guidance for practitioners and organisations delivering these schemes.

- We end with a call to all in the physical activity and health sector to engage with The National Referral Database and its further development; for those who are delivering schemes to ensure they are capturing data and look to contribute this to the database; for researchers to engage with the available data in order to answer key questions and enhance understanding of exercise and wider physical activity referral schemes; and for policy makers and practitioners to pay attention to, and ensure they utilise the insights gleaned from this work. 


\title{
The National Referral Database: An initial overview
}

\author{
Steele, J. ${ }^{1,2}$, Wade, M. ${ }^{1,3}$, Polley, M. ${ }^{4}$, Copeland, R. ${ }^{5}$, Stokes, S. ${ }^{6}$, Mann, S. ${ }^{7}$
}

${ }^{1}$ Research Institute, ukactive, London, UK, ${ }^{2}$ Solent University, Hampshire, UK, ${ }^{3}$ St Mary's University, London, UK, ${ }^{4}$ University of Westminster, London, UK, ${ }^{5}$ The National Centre for Sport and Exercise Medicine, Sheffield, UK, ${ }^{6}$ ReferAll Ltd, Worthing, UK, ${ }^{7}$ Places for People Leisure, UK; Contact for Correspondence: jamessteele@ukactive.org.uk; Twitter: @jamessteeleii

\section{SCIENTIFIC ABSTRACT}

Background: In 2014 The National Institute for Health and Care Excellence (NICE) called for development of a system to collate local data on exercise referral schemes (ERS) to inform future practice. This database would be used to facilitate continued evaluation of ERS. 'Big data' analytics is a current trend in healthcare with the potential to influence decision making. Indeed, the use of health databases can spur scientific investigation and generation of evidence regarding healthcare practice. NICEs recommendation has not yet been met by public health bodies. However, through collaboration between ukactive, ReferAll, a specialist in software solutions for exercise referral, and the National Centre for Sport and Exercise Medicine, data has been collated from multiple UK based ERS to generate one of the largest databases of its kind and move towards meeting NICEs recommendation. Method: This paper describes the formation of The National Referral Database, its structure including outcome measures, data cleaning processes, and in two accompanying manuscripts the first initial observational insights are presented from analysis of this data. Results: Collating data from 19 ERSs on 24,086 individuals, a database has been created containing pre and post referral data for metrics including; physical activity, blood pressure, BMI, resting heart rate, SWEMWBS scores, ESES scores, WHO5 scores and ERQoL scores. After data cleaning processes there were 14 ERSs remaining covering 23,782 participants with an average age of $51 \pm 15$ years and $68 \%$ of whom were female. Further, the database contains demographic information, reason for referral, medical conditions, and information on the referrer. Conclusion: This database has now been created and the initial data is available for researchers to interrogate. The National Referral Database represents a potentially valuable resource for the wider research community, as well as policy makers and practitioners in this area, which will facilitate a better understanding of ERS and other physical activity related social prescribing pathways to help inform public health policy and practice. Longer term plans include establishment of the database as an open resource, continually updated with additional data and version controls, for researchers to access for further research and policy makers and practitioners to use to inform their policies/practices.

Key words: health database; exercise referral; physical activity; big data

\section{INTRODUCTION}

The National Institute for Health and Care Excellence (NICE) published guidelines regarding exercise referral schemes (ERS) in 2014 (NICE, 2014). The extant literature at the time regarding the impact of ERS was considered inadequate, with inconsistent and weak evidence regarding their effects upon health, wellbeing, and quality of life outcomes (Pavey et al., 2011; NICE, 2014; Duda et al., 2014; Dugdill et al., 2005). A recent systematic review has highlighted that ERSs in the UK may be effective in increasing physical activity and that longer schemes ( $\geq 20$ weeks) may be more so than shorter schemes $(\leq 12$ weeks; Rowley et al., 2018). However, it has been argued that physical activity promotion within primary care should extend beyond just ERS incorporating wide social prescribing of physical activity. Moreover, the impact of these programmes should be assessed against outcomes beyond merely increasing physical activity levels to other health and wellbeing outcomes (Orrow et al., 2012).

The world of ERSs has recently been described as 'wild and woolly' lacking clarity in the conceptualisation of 'exercise' and little stakeholder agreement in how to determine 'impact' (Henderson et al., 2018). Henderson et al. (2018) have argued that ERSs do not work per se, but that their effectiveness is determined by the interpretations of their participants and whether they 'improve' on an individual basis. Yet, while important to the person, change at the individual level does not facilitate understanding of whether an effect exists within a population, nor the size of that effect and the precision with which it can be estimated. These are important factors to consider when developing policies and commissioning programmes and interventions. Indeed, it has been argued (Beedie et al., 2016) that 
sport and exercise medicine has for some time been drowning in a body of evidence regarding 'efficacy' (the extent to which an intervention has the ability to bring about an intended effect under ideal circumstances e.g. in laboratory settings) whilst simultaneously dying of thirst from a lack of evidence regarding 'effectiveness' (the extent to which an intervention achieves its intended effect in its usual setting). If population health change is a goal of stakeholders, particularly those determining strategy and policy or delivering programmes and interventions, then research examining effects from ecologically valid datasets are needed to determine effectiveness and compliment the evidence base examining efficacy. No large scale evaluation of the effectiveness of ERSs has yet been conducted in the UK. As such there is scope for work to establish on a larger scale whether ERSs and other physical activity related referral pathways are indeed effective in improving the health and wellbeing of those participants undergoing them.

One of the recommendations made in the 2014 guidelines from NICE was that "Public Health England should develop and manage a system to collate local data on exercise referral schemes" and that these data should be based upon the Standard Evaluation Framework for physical activity interventions. Furthermore, that data should be made available (in a useable format) for analysis and research to inform future practice. 'Big data' analytics is a current trend in healthcare and it has been argued that within it lies the potential to transform the way policy, commissioning, and delivery decisions are made in healthcare contexts (Raghupathi \& Raghupathi, 2014). Indeed, the use of health databases has been argued to have considerable impact upon promotion of scientific production (Chen et al., 2011). A resource such as this has yet to be produced. However, The National Referral Database is a newly formed resource produced in collaboration by ukactive, the National Centre for Sport and Exercise Medicine in Sheffield, and ReferAll, which includes data on a variety of outcomes for patients both pre and post their ERS participation. The National Referral Database represents the largest database, and in essence is the largest longitudinal study, of ERS in the UK and satisfies the call from NICE (2014). Indeed, in recent consultation NICE removed this recommendation from the guidelines primarily for the reason of the emergence of The National Referral Database satisfying their early recommendation (NICE, 2018). The potential of this database is significant given the NRD offers researchers, policy makers, practitioners and clinician's access to myriad observational data through which to explore what works and what doesn't work in terms of ERS.

The aim of this paper is to describe the formation of The National Referral Database. Additionally, two accompanying manuscripts presenting initial insights that have been provided from the first phase analysis of the existing data. Within this initial overview present limitations of the database and analyses alongside future plans for analysis and development of the database will be discussed, and a call made for researchers, practitioners, and policy makers to engage with it in order to facilitate better evaluation of ERS and other physical activity referral schemes in the future.

\section{METHODS}

Study Design

Between September 2011 and December 2017 (the present data cut), The National Referral Database included 24,086 participants undergoing an ERS. Participants had been referred into, provided informed consent to participate in, and attended, an ERS at one of 19 sites across the UK. At each site participants underwent initial screening and pre-testing, completed an exercise/physical activity based intervention, and were followed-up 
Table 1. Characteristics included in database for schemes and participants

\begin{tabular}{|c|c|}
\hline Characteristic & Options \\
\hline Scheme length & 3 months (90 days); 12 weeks ( 84 days); 6 weeks (42 days) \\
\hline Referrer organisation & $\begin{array}{c}\text { Community; Hospital; Medical Centre; Outreach Centre; } \\
\text { Pharmacy; Surgery }\end{array}$ \\
\hline Referrer type & $\begin{array}{l}\text { Adult Nurse; Advanced Nurse Practitioner; Alcohol Liaison } \\
\text { Nurse; Alcohol Enforcement and Strategy Manager; Cardiac } \\
\text { Nurse; Cardiac Physiotherapist; Cardiac Sister; Cardiographer; } \\
\text { Clinical Nurse Specialist; Clinical Psychologist; Community } \\
\text { Diabetes Team; Community Mental Health Worker; Community } \\
\text { Physiotherapist; Community Psychiatry Nurse; Consultant; } \\
\text { Consultant Psychiatrist; Counsellor; Dietician; Doctor; Exercise } \\
\text { Specialist; Family Support Worker; General Practitioner; Health } \\
\text { Education and Promotion Worker; Health Improvement Officer; } \\
\text { Health Improvement Practitioner; Health Support Worker; Health } \\
\text { Trainer; Health Trainer Coordinator; Health Visitor; Healthcare } \\
\text { Assistant; Healthy Lifestyle Motivator; Lead Nurse Diabetes; } \\
\text { Mental Health Nurse, Mental Health Practitioner; Mental Health } \\
\text { Support Worker; Mental Health Worker; NHS Health Check } \\
\text { Nurse; Nurse; Nursing Assistant; Occupational Therapist; Other } \\
\text { Healthcare Professional; Pharmacist; Phase III Falls Specialist; } \\
\text { Physiotherapist; Physiotherapy Assistant; Podiatrist/Chiropodist; } \\
\text { Practice Nurse; Psychiatrist; Psychologist; Psychotherapist; } \\
\text { Recovery Worker; Respiratory Physiologist Technician; } \\
\text { Respiratory Therapist Rheumatology Nurse; Self-Referral; Senior } \\
\text { Health Trainer; Senior Physiotherapist; Social Worker; Specialist } \\
\text { Health Improvement Practitioner; Surgeon; Technical Instructor; } \\
\text { Therapy Assistant }\end{array}$ \\
\hline Postcode & N/A \\
\hline $\begin{array}{l}\text { Ethnicity/Ethnicity group } \\
\text { Age at referral }\end{array}$ & $\begin{array}{l}\text { Asian; Black; Mixed; Other; Unknown/Withheld; White } \\
\text { N/A }\end{array}$ \\
\hline Sex/Gender & Male; Female; Transgender \\
\hline Disability status & $\begin{array}{l}\text { Blind or serious visual impairment; Cognitive impairment (such } \\
\text { as autistic spectrum disorder or resulting from a head injury); } \\
\text { Deaf or serious hearing impairment; General learning disability } \\
\text { (such as Down's Syndrome; Not disabled; Long standing illness } \\
\text { or health condition (such as cancer, HIV, diabetes, or epilepsy); } \\
\text { Mental health condition (such as depression or schizophrenia); } \\
\text { Other type of disability; Physical impairment; Prefer not to say; } \\
\text { Registered learning disability; Specific learning disability (such } \\
\text { as dyslexia); Unknown }\end{array}$ \\
\hline Employment status & $\begin{array}{l}\text { Carer; Employed full time; Employed full time/part time; } \\
\text { Employed in intermediate occupation (i.e. call centre agent or } \\
\text { clerical worker); Employed in managerial or professional } \\
\text { occupation; Employed part time; Full time carer; Looking after } \\
\text { home/family full time; Other; Permanently sick/disabled; Retired; } \\
\text { Self-employed; Student; Unemployed; Unknown; Volunteer }\end{array}$ \\
\hline Marital status & $\begin{array}{l}\text { Civil partnership; Co-habiting; Divorced; Married; Prefer not to } \\
\text { say; Separated; Single; Unknown; Widowed }\end{array}$ \\
\hline
\end{tabular}

post scheme. In essence, this database represents a longitudinal study design following individuals entering and exiting an ERS.

\section{Exercise Referral Schemes}

Nineteen ERSs were included in the The National Referral Database at the time of its formation (more ERS data exists within the wider ReferAll system but not all have consented to include data in the database at present). What proportion of ERSs in the UK this represents is unclear. Pavey et al. (2011) claim 600 ERSs were being delivered in the UK though this figure has no supporting data and so its veracity is uncertain. Data available pertaining to the characteristics of schemes and participants including options where applicable are included in table 1. Available data pertaining to the characteristics of schemes and their participants are shown in table 2. Specific information regarding the exact nature of the schemes employed is unknown. The collection of this descriptive data regarding the 'active components' of ERS in the database, and any newly joined ERSs for future versions of the database, is 
currently being collected via survey following the Consensus on Exercise Reporting Template (CERT; Slade et al., 2016) and it is intended that going forwards new schemes will be requested to include this data upon entry.

\section{Measures}

Outcome measures varied across the ERS (see tables 2 and 4 ) but were taken at both pre- and post-intervention across all ERSs. The majority of schemes included height and weight and from this body mass index (BMI) could be calculated. Physical activity levels were assessed using the International Physical Activity Questionnaire (IPAQ) short form. This examined self-reported physical activity levels and contains 7 open-ended items regarding the participants' last 7-day recall of physical activity. Items are structured to provide scoring on walking, moderateintensity and vigorous-intensity activity, in addition to sitting. The IPAQ has been designed for observational research and its test-retest reliability indicates good stability and high reliability along with concurrent validity (Craig, et al. 2003; Lee, et al. 2011). Blood pressure (Pickering et al., 2005), systolic (SBP) and diastolic (DBP), and resting heart rate were also included as outcomes in the majority of schemes. Mental wellbeing was included and measured in a small number of ERS using the short Warwick Edinburgh Mental Wellbeing Scale (SWEMWBS; StewartBrown et al., 2009) and general wellbeing and quality of life using the World Health Organization Well-Being Index (WHO-5; Topp et al, 2015), and Exercise Related Quality of Life scale (ERQoL; Hilton et al., 2015). Lastly, exercise related self-efficacy was collected in one scheme using the Exercise Self-Efficacy Scale (Kroll et al., 2007).

\section{Data Cleaning}

Data cleaning (Van den Broeck et al., 2005) was performed due to the size of the database and the fact that information was inputted manually at the source of collection by ERS staff. As noted, the data cut used here contained data from 24,086 participants; however, examination of data highlighted that most outcomes contained data outside of plausible ranges based upon

Table 2. Characteristics of participants across schemes.

\begin{tabular}{ccc}
\hline Scheme Number & Age (Mean \pm SD) & $N$ (Female:Male) \\
\hline 5001 & $56 \pm 17$ & $1264(738: 526)$ \\
5002 & $48 \pm 12$ & $3736(2815: 921)$ \\
5026 & $49 \pm 13$ & $2070(1596: 474)$ \\
5028 & $48 \pm 11$ & $151(111: 40)$ \\
5036 & $51 \pm 15$ & $3736(2692: 1044)$ \\
5051 & $48 \pm 17$ & $3(1: 2)$ \\
5056 & $50 \pm 15$ & $4574(3012: 1562)$ \\
5063 & $45 \pm 11$ & $325(237: 88)$ \\
5072 & $48 \pm 12$ & $1735(1285: 450)$ \\
5089 & $56 \pm 15$ & $1670(993: 677)$ \\
5108 & $51 \pm 16$ & $591(413: 177)$ \\
5114 & $49 \pm 16$ & $127(79: 48)$ \\
5115 & $57 \pm 14$ & $853(469: 384)$ \\
5119 & $59 \pm 18$ & $51(26: 25)$ \\
5131 & $50 \pm 16$ & $1628(985: 643)$ \\
5135 & 80 & $1(1: 0)$ \\
5144 & $53 \pm 17$ & $450(271: 179)$ \\
5151 & $48 \pm 17$ & $22(16: 6)$ \\
5156 & $59 \pm 15$ & $1099(680: 419$ \\
\hline All schemes & $51 \pm 15$ & $24086(16420: 7665)^{*}$
\end{tabular}

*Note: one participant identified as transgender 
Table 3. Data cleaning summary - Cleaning processes followed the order 'pre', 'post', then 'change' descriptive statistics are for change scores (post- minus pre-).

\begin{tabular}{|c|c|c|c|c|c|}
\hline & $\begin{array}{c}\text { Complete pre- and } \\
\text { post-ERS data }\end{array}$ & $\begin{array}{l}\text { Cut-offs for pre- } \\
\text { and post-ERS data }\end{array}$ & $\begin{array}{l}\text { Pre- and post-ERS } \\
\text { data after cleaning }\end{array}$ & $\begin{array}{l}\text { Cut-offs for changes } \\
\text { in each outcome }\end{array}$ & $\begin{array}{c}\text { Sample after all } \\
\text { cleaning }\end{array}$ \\
\hline \multicolumn{6}{|c|}{ IPAQ (total MET-mins) } \\
\hline Mean \pm SD & \multirow{3}{*}{\multicolumn{4}{|c|}{ Standard cleaning and analysis procedures for the IPAQ were followed }} & $652 \pm 1600$ \\
\hline Range & & & & & -13746 to 13086 \\
\hline Schemes & & & & & 12 \\
\hline \multicolumn{6}{|c|}{ BMI* (kg.m $\left.{ }^{2}\right)$} \\
\hline Mean \pm SD & $293.03 \pm 7457.11$ & Height - Pre/post & $-0.33 \pm 1.80$ & Height - Change & $-0.49 \pm 0.90$ \\
\hline Range & -527.30 to 346839.25 & cleaned to range of & -41.40 to 21.74 & cleaned to TEM of & -6.02 to 0.90 \\
\hline$N$ & 7548 & $122.5 \mathrm{~cm}$ to $205 \mathrm{~cm}$ & 7473 & $0.32 \mathrm{~cm}$ (Geeta et al., & 4835 \\
\hline Schemes & 12 & Weight - Pre/post & 12 & 2009) & 12 \\
\hline & & $\begin{array}{l}\text { cleaned to range of } \\
40 \mathrm{~kg} \text { to } 180 \mathrm{~kg}\end{array}$ & & $\begin{array}{c}\text { Weight - Change } \\
\text { cleaned to }-15 \mathrm{~kg} \text { to } 2 \\
\mathrm{~kg} \text { (King et al., 2008) }\end{array}$ & \\
\hline \multicolumn{6}{|c|}{$\underline{\operatorname{RHR}\left(f_{\mathrm{c}}\right)}$} \\
\hline Mean \pm SD & $-5.26 \pm 25.43$ & Pre/post cleaned & $0.96 \pm 11.15$ & Change cleaned to a & $0.49 \pm 7.26$ \\
\hline Range & -110 to 540 & range to $40 f_{\mathrm{c}}$ to & -47 to 52 & range of $-15 f_{\mathrm{c}}$ to $15 f_{\mathrm{c}}$ & -15 to 15 \\
\hline$N$ & 6905 & $110 f_{\mathrm{c}}$ (An et al., & 6266 & (selected as & 5289 \\
\hline Schemes & 10 & 1999) & 10 & $\begin{array}{c}\text { reasonable due to } \\
\text { lack of change ranges } \\
\text { in literature) }\end{array}$ & 10 \\
\hline \multicolumn{6}{|c|}{$\underline{\mathrm{SBP}(\mathrm{mmHg})}$} \\
\hline Mean \pm SD & $-3.52 \pm 23.56$ & Pre/post cleaned & $-1.98 \pm 14.66$ & Change cleaned to a & $-2.33 \pm 13.71$ \\
\hline Range & -196 to 167 & range to $60 \mathrm{mmHg}$ & -83 to 89 & range of $-55 \mathrm{mmHg}$ & -55 to 35 \\
\hline$N$ & 7653 & to $200 \mathrm{mmHg}$ & 7479 & to $35 \mathrm{mmHg}$ (Winett & 7393 \\
\hline Schemes & 13 & & 13 & et al., 2014) & 13 \\
\hline \multicolumn{6}{|c|}{ DBP $(\mathrm{mmHg})$} \\
\hline Mean \pm SD & $-1.96 \pm 25.70$ & Pre/post cleaned & $-1.08 \pm 9.00$ & Change cleaned to a & $-1.11 \pm 8.84$ \\
\hline Range & -775 to 789 & range to $30 \mathrm{mmHg}$ & -58 to 52 & range of $-55 \mathrm{mmHg}$ & -55 to 35 \\
\hline$N$ & 7653 & to $110 \mathrm{mmHg}$ & 7462 & to $35 \mathrm{mmHg}$ (Winett & 7455 \\
\hline Schemes & 13 & & 13 & et al., 2014) & 13 \\
\hline \multicolumn{6}{|c|}{ WHO-5 (pts) } \\
\hline Mean \pm SD & $2.19 \pm 5.22$ & Pre/post cleaned & $2.19 \pm 5.22$ & N/A & $2.19 \pm 5.22$ \\
\hline Range & -11 to 19 & range 0 pts to 25 & -11 to 19 & & -11 to 19 \\
\hline$N$ & 449 & pts - impossible & 449 & & 449 \\
\hline Schemes & 1 & $\begin{array}{l}\text { scores based on } \\
\text { scale were also } \\
\text { cleaned }\end{array}$ & 1 & & 1 \\
\hline \multicolumn{6}{|c|}{ SWEMWBS (pts) } \\
\hline Mean \pm SD & $2.16 \pm 4.84$ & Pre/post cleaned & $2.14 \pm 4.82$ & N/A & $2.14 \pm 4.82$ \\
\hline Range & -15.75 to 28 & range 7 pts to 35 & -15.75 to 28 & & -15.75 to 28 \\
\hline$N$ & 1626 & pts - impossible & 1625 & & 1625 \\
\hline Schemes & 3 & $\begin{array}{l}\text { scores based on } \\
\text { scale were also } \\
\text { cleaned (Stewart- } \\
\text { Brown et al., } \\
\text { 2009) }\end{array}$ & 3 & & 3 \\
\hline \multicolumn{6}{|c|}{ ERQoL (pts) } \\
\hline Mean \pm SD & $19.57 \pm 18.69$ & Pre/post cleaned & $19.45 \pm 17.30$ & N/A & $19.45 \pm 17.30$ \\
\hline Range & -66 to 87 & range 22 pts to 110 & -52 to 66 & & -52 to 66 \\
\hline$N$ & 789 & pts - impossible & 779 & & 779 \\
\hline Schemes & 4 & $\begin{array}{l}\text { scores based on } \\
\text { scale were also } \\
\text { cleaned (Hilton et } \\
\text { al., 2015) }\end{array}$ & 4 & & 4 \\
\hline \multicolumn{6}{|c|}{ ESES (pts) } \\
\hline Mean \pm SD & $2.58 \pm 6.62$ & Pre/post cleaned & $2.58 \pm 6.62$ & N/A & $2.58 \pm 6.62$ \\
\hline Range & -16 to 20 & range 4 pts to 40 & -16 to 20 & & -16 to 20 \\
\hline$N$ & 252 & pts - impossible & 252 & & 252 \\
\hline Schemes & 1 & $\begin{array}{l}\text { scores based on } \\
\text { scale were also } \\
\text { cleaned (Kroll et } \\
\text { al., 2007) }\end{array}$ & 1 & & 1 \\
\hline
\end{tabular}

*Note: BMI data is based upon cleaning of height and weight from which BMI was calculated

the measure and its unit of measurement. It is likely that this was the result of data entry errors. There were also missing data for paired comparisons either at pre- or post- 
ERS time points and thus, for the present study, the database was first cleaned to yield only paired data for which there was both pre- and post-ERS time points present (i.e. participants with missing data points were excluded). Afterwards the pre-, and then post-, ERS values were screened with respect to their range and upper and lower cut-offs used to exclude data based upon either previous reports including typical ranges for physiological variables, or possible ranges for questionnaire based data based upon scoring systems used. The physiological change data was then checked and data excluded where it exceeded upper and lower cut-offs based upon previously reported ranges for change in exercise/physical activity interventions. IPAQ data was handled using standard procedures for cleaning and analysis. Table 3 shows the starting number of complete pairs of data (i.e. both pre- and post-ERS time points present), and the cut-offs used for data exclusion in addition to the number of participant's data left remaining after cleaning for each outcome measure. Number of schemes at each stage are also included. Data editing was not performed (the exception being for IPAQ wherein the standard guidelines were followed) as in most cases it was impossible to determine satisfactory rules to address potential reasons for incorrect input of values (e.g. in the height field a value may read ' 69 ' and as this field is supposed to be in $\mathrm{cm}$ it is plausible that the person entering the data accidentally missed the ' 1 ' of the start and it should be ' $169 \mathrm{~cm}$ ', in addition to its being plausible that they incorrectly entered it in inches which would mean it should be ' 175.3 cm'). Descriptive statistics (means and standard deviations) and ranges are shown for each variable and each outcome measure (pre- to post-ERS change) in table 3 to present changes based upon cleaning procedures. Lastly, outcomes from schemes with insufficient data $(n<4)$ were excluded.

\section{RESULTS}

At the time of formation, the database contained nineteen ERSs covering 24,086 participants with an average age of $51 \pm 15$ years and $68 \%$ of whom were female (Table 2). After data cleaning processes (Table 2) there were 14 schemes remaining covering 23,782 participants with an average age of $51 \pm 15$ years and $68 \%$ of whom were female (Table 4). Table 3 shows the schemes and participant characteristics available after data cleaning, however there was not complete data for all of these schemes for all outcomes for all participants (i.e. both pre- and post-ERS measures). The total samples for each outcome measure (both number of schemes and number of participants) are already reported in addition to descriptive statistics (mean \pm SD and ranges) for each stage of the data cleaning in Table 2, and the final

Table 4. Characteristics for participants of schemes included in database after cleaning.

\begin{tabular}{ccc}
\hline Scheme Number & Age (Mean \pm SD) & $N$ (Female:Male) \\
\hline 5001 & $56 \pm 17$ & $1264(738: 526)$ \\
5002 & $48 \pm 12$ & $3736(2815: 921)$ \\
5026 & $49 \pm 13$ & $2070(1596: 474)$ \\
5036 & $51 \pm 15$ & $3736(2692: 1044)$ \\
5056 & $50 \pm 15$ & $4574(3012: 1562)$ \\
5063 & $45 \pm 11$ & $325(237: 88)$ \\
5072 & $48 \pm 12$ & $1735(1285: 450)$ \\
5089 & $56 \pm 15$ & $1670(993: 677)$ \\
5108 & $51 \pm 16$ & $591(413: 177)^{*}$ \\
5115 & $57 \pm 14$ & $853(469: 384)$ \\
5119 & $57 \pm 21$ & $51(26: 25)$ \\
5131 & $50 \pm 16$ & $1628(985: 643)$ \\
5144 & $53 \pm 17$ & $450(271: 179)$ \\
5156 & $59 \pm 15$ & $1099(680: 419)$ \\
\hline All schemes & $51 \pm 15$ & $23782(16212: 7569)^{*}$
\end{tabular}

*Note: one participant identified as transgender 
column of Table 2 shows the final samples included in analysis. Table 5 shows the preERS scores across the schemes for each of the outcome measures examined. Table 6 shows pre- and post ERS $n$ 's for each outcome. Both the uncleaned original data, and each cleaned variables data, are available individually in csv file format currently upon request from the corresponding author.

\section{DISCUSSION}

Despite widespread adoption, research exploring the effect of ERS on health outcomes from ecologically valid datasets is scarce. This manuscript describes the formation of The National Referral database; a UK wide database of ERS based on the Standard Evaluation Framework for physical activity interventions. In the two manuscripts accompanying this output we report on analyses performed with the intention of considering broadly; do we observe a meaningful effect for health and wellbeing outcomes, and physical activity levels, in people who are undergoing ERSs? Though currently there is a lack of agreement of what constitutes 'impact' with respect to the evaluation of ERS (Henderson et al., 2018), the evidence presented in these two accompanying manuscripts does little to support the current use of ERSs, broadly speaking. However, with the development and management of The National Referral Database as an open resource, we hope that continued evaluation will enable standards to be lifted and identification of which ERS and other physical activity referral schemes are effective.

Big data analytics is a current trend in healthcare and it has been argued that within it lies the potential to transform the way in which decisions are made (Raghupathi \& Raghupathi, 2014). The National Referral Database does not yet meet the definition of 'big data' (defined as: $\log \left[\begin{array}{lll}n * & p\end{array}\right] \geq 7$; Baro et al., 2015; considering both outcomes and other characteristics The National Referral
Database $=\log [23,782 * 21]=5.7)$, though it does still represent, to our knowledge, the largest database of ERS in the UK. With the addition of further information regarding existing ERS, in addition to ongoing incorporation of data both from existing and new schemes, there is the potential to move towards 'big data' and for more precise decisions with respect to both groups, and possibly individuals, as to which interventions might work best for whom and under what circumstances.

The current findings reported in the accompanying manuscripts suggest that, broadly speaking, there is likely only little benefit with respect to the effects of ERS at a population level upon changes in physical activity levels, as well as health and wellbeing outcomes (Wade et al., 2019; Rowley et al., 2019). Yet it may be that this is a result of the schemes and their participants differing in factors that influence the effects. The NRD is in its infancy and it is therefore important to recognize that early findings are likely skewed by heterogeneity in scheme design. With respect to exercise based interventions, there is not so much doubt as to the efficacy of physical activity and exercise for improving various health and wellbeing related outcomes and indeed various studies support this (see accompanying manuscripts discussions). However, in their current form and broadly speaking, ERSs do not seem to be resulting in the effectiveness that might be expected based upon the apparent efficacy of exercise and physical activity. The continued growth and use of The National Referral Database might better enable the standardization of ERSs with respect to intervention components and treatment fidelity and this in itself is likely to positively influence the quality of ERS their effect at the population level. Standardization has been noted also as being difficult for a host of sociological reasons (Henderson et al., 2018). Though it does not address the potential barriers to standardization Henderson et al. (2018) 


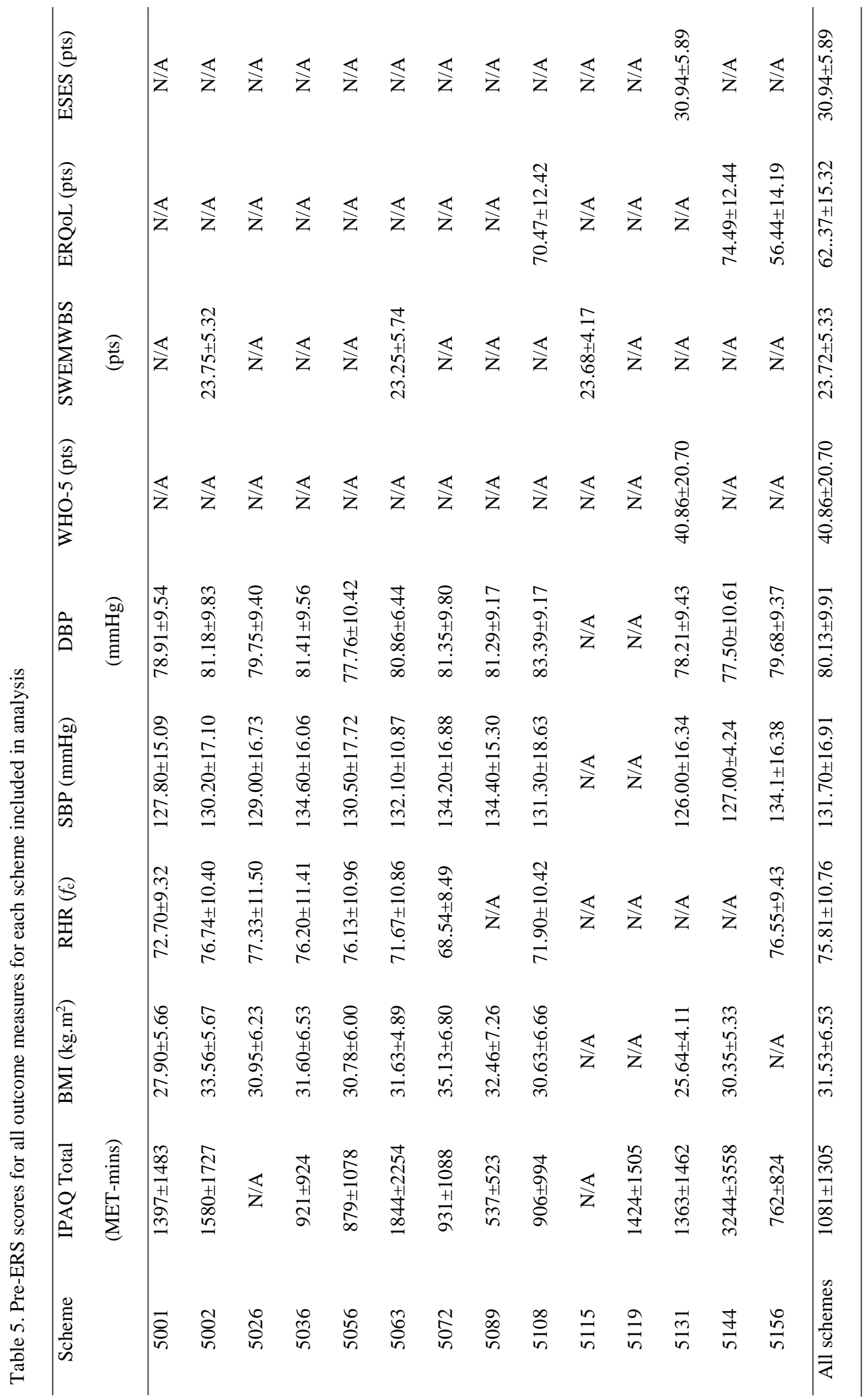


Table 6. Number of participants at pre- and post-ERS time points.

\begin{tabular}{cccc}
\hline Outcome measure & Pre $(n)$ & Post $(n)$ & Proportion at follow up $(\%)$ \\
\hline IPAQ & 20312 & 7391 & 36.4 \\
BMI & 21420 & 7795 & 36.4 \\
RHR & 18849 & 7120 & 37.8 \\
SBP & 21564 & 7908 & 36.7 \\
DBP & 21564 & 7908 & 36.7 \\
WHO-5 & 1620 & 456 & 28.2 \\
SWEMWBS & 4649 & 1723 & 37.0 \\
ERQoL & 2176 & 796 & 36.6 \\
ESES & 1160 & 342 & 29.5 \\
\hline
\end{tabular}

highlight, a seemingly obvious place to start is with a robust evidence base on which there is at least agreement on what does work best at a population level. Implementation of standardization then at least has a starting point.

Alternatively, the lack of effectiveness may reflect issues with translation and implementation of interventions used in standardized settings (such as with supervised ERSs employed in RCTs) in reflecting local needs. Indeed, intervention fidelity is an issue of considerable importance for healthcare interventions (Borrelli, 2011). Considering this, recently there has been development of a framework for co-production of ERSs alongside multidisciplinary stakeholders as a novel approach (Buckley et al., 2018). Further, though evidence at present is limited (Bickerdike et al., 2017), the use of wider social prescribing to address other areas of support that individuals might need to tackle first in order to facilitate their wider health and wellbeing is being widely promoted including in the recent National Health Service (NHS) Long Term Plan (NHS, 2019). Link worker social prescribing based have been suggested as an approach to help achieve this whereby support is provided to patients across wider personal issues (Moffat et al., 2017). It seems likely that there is a need for both standardization to ensure that ERS and other physical activity referral schemes are evidence based with respect to their ability to produce the desired effects, and codevelopment on a local level to ensure that implementation considers wider personal issues and barriers to ensuring ERSs can succeed in achieving this. 'Big data' in this field might better enable to comparative evaluation of different schemes in addition to the effects of scheme fidelity upon effectiveness.

Another current trend that runs parallel to that of 'big data' is 'precision medicine'. Indeed, the notion of 'precision medicine' is currently a popular topic, albeit not one without criticism (Coote and Joyner, 2015). The results reported accompanying this manuscript do evidence that there is considerable heterogeneity between ERSs for all outcomes. Yet it should also be noted that the demographics, conditions, pathways etc. of the participants within the database were also varied and thus there may be individual level factors influencing the responsiveness. For example, there may be potential benefit in the examination of identifying who responds best to which interventions and what are the predictors at the individual level of this. Indeed, 'big data' has been argued to be valuable in the quest towards 'precision medicine' (Leff and Yang, 2015) and the establishment of The National Referral Database could in theory contribute towards that end. However, at present, though it represents the largest database of ERS in the UK, it is not yet at a point whereby such findings can be elucidated. The data included are pre- and post-ERS longitudinal outcomes and without the use of appropriate controls from which to determine whether true interindividual variation is indeed identifiable for these outcomes it is difficult to identify meaningful predictors (Atkinson and Batterham, 2015). Instead perhaps a better 
understanding of what specific populations (e.g. those referred with type II diabetes, or cardiovascular disease, or musculoskeletal disorders; Rowley et al., 2018), which specific ERSs work best comparatively, or indeed a combination of these two (i.e. what works best for which population) may be the next step in generating evidence to help guide the implementation of ERSs. Further, in addition to understanding at a population level what effects ERSs may have upon those with specific conditions (indeed this is often the most reliable indicator of individual level effects; Atkinson \& Batterham, 2015), realist reviews of what approaches to ERSs work, for whom, and within what context are likely needed to ensure successful transfer of these effects to patients and indeed this approach is being taken to understand wider social prescribing schemes (Husk et al., 2016; Berlotti et al., 2018).

It should be noted that The National Referral Database at present, along with the accompanying analyses presented, are not without several limitations. Whilst, we have given consideration to future plans for the database in order to improve its quality and the insights that it might yield, it is important to be mindful of the infancy of this project. Briefly, the data here are observational in nature (in essence they show the change over time of participants of ERSs). Thus, without an appropriate control group there is the clear problem of the counterfactual which renders it unclear whether any changes that have been observed might have resulted causally from participation in the ERSs. Further, though where possible in the accompanying analyses we based our tests upon null intervals (as opposed to point nulls i.e. a change of zero) around what were considered as minimal clinically important changes in the extant literature for calculation of second generation $\mathrm{p}$ values (Blume et al., 2018), it may be that these are inappropriate and indeed many of the statistically significant changes could be deemed meaningful also. This said, other evidence from RCTs suggests that, for many of the outcomes examined, exercise can produce statistically significant and meaningful changes (see accompanying manuscripts discussions), but that in the ecologically valid examination of ERSs as currently employed here these changes do not manifest to the same degree possibly due to other confounding variables.

Details of the schemes included in the database is also an issue. For example, with respect to length of scheme there is currently only one scheme of 6 weeks prohibiting comparison of scheme lengths. Longer schemes may be 'better' for adherence (Rowley et al., 2018). Recent work suggests additional support alongside traditional ERSs might improve adherence longer term (Martin-Borras et al., 2017) and more research is planned to examine this (Hawkins et al., 2017). Over time the addition of longer schemes to the database may aid understanding of the role of scheme length. Further to this, the database currently lacks information regarding the specific details of the schemes exercise or physical activity components. This is a major limitation in drawing conclusions regarding what might work in terms of specific ERS and which presents an issue as, at the level of determining strategic implementation of schemes whether private or public sector, there appears to be differences in how 'exercise' or 'physical activity' is conceptualized (Henderson et al., 2018). However, as already mentioned, this data is presently being collected from existing ERSs in the database, and it is intended it will be collected from any newly joined schemes, following the CERT guidelines (Slade et al., 2016). Further, monitoring of intervention fidelity utilizing known treatment fidelity frameworks will be essential to enhance the understanding of the feasibility of wider implementation should effectiveness be identified (Borrelli, 2011).

Lastly, the accompanying analyses did not consider participant characteristics (e.g. age, sex, disability, employment 
status, ethnicity, socioeconomic status, referral pathways, referral reasons etc.) and how that might moderate changes over time from participation. This is partly due to variety of present options with respect to many of these variables currently captured and future work will look to better classify and group these variables. However, similar issues apply here with respect to determining the impact of these factors for the individual with respect to predicting responsiveness without sufficient understanding of typical long term variability in outcome measures independently of any intervention (i.e. to identify if someone is a true high or low individual responder; Atkinson and Batterham, 2015). Inclusion of monitoring of wait-list controls for any schemes that use them in the database could improve research designs, and address to some degree the problem of the counterfactual thus improving the ability to make causal inferences. Such inclusion might permit the The National Referral Database to facilitate large simple trials in a similar manner to other databases and electronic health records (Roundtable on Value and ScienceDriven Health Care, 2013). Future work is already planned and/or underway to explore drop out/loss to follow up (the average proportion of participants at follow was only $\sim 35 \%$ ), the outcomes routinely collected from ERS and their appropriateness, in addition to whether ERS schemes are presently targeting and including those for whom they are intended based upon NICE guidelines.

\section{CONCLUSION AND FUTURE PLANS FOR DATABASE DEVELOPMENT}

The National Referral Database represents a potentially valuable resource for the wider research community, as well as policy makers and practitioners in the area of physical activity and public health. It has the potential to facilitate a better understanding of ERS and other physical activity referral pathways to help inform public health policy and practice. Longer term plans include establishment of The National Referral Database as an open resource, continually updated with additional data and version controls, for researchers to access and policy makers and practitioners to use to inform their policies/practices. The set-up of an online hosting platform is currently being explored and it is envisioned that the database and platform will have the following functionality:

- Users could register requests for data access and as part of this specify their research questions and proposed analysis plans.

- Proposed research questions and analysis plans would be made publicly available as 'pre-registered' upon approval of the request so as to avoid duplication of efforts from different research teams, and also to avoid 'data mining'/'p-hacking'. Further, it will be expected that results of pre-registered plans will be reported back and these reports hosted on the platform including links to any subsequent publications in other outlets (i.e. peer reviewed journal articles). In essence this would act similarly to 'Registered Reports' wherein, assuming the proposed plans for the research are accepted, the full reporting of the research in line with this would be accepted for publication and hosted on the service ${ }^{1}$.

- The platform would directly integrate with ReferAll's existing system to enable continued updating of the database on a regular schedule from existing schemes as new participants enter them, and as new schemes sign up to deposit their data. Further, schemes not utilizing ReferAll's service would be provided with functionality to allow

\footnotetext{
${ }^{1}$ There has been a recent call for the field of sport and exercise science, and its wider associated disciplines, to move towards a Registered Reports approach to conduct and communication of research (Caldwell et al., 2019).
} 
them to upload historic or ongoing data directly to the database.

- Due to this the platform would also have version control so that researchers are aware of updates and any reports can be linked back to the correct versions of the database.

- Lastly, dashboards and reporting of descriptive data and results of analyses, as well as hosting of full research reports would be incorporated to facilitate transmission of findings to policy makers and practitioners.

Though not a requirement for health research databases in the UK, ethical approval from the Health Research Authority will be sought to ensure due diligence. Furthermore, all potential users of The National Referral Database for research would be required to evidence that they have obtained independent ethical approval (i.e. institutional ethics committee/IRB) for research questions and proposed analysis plans prior to gaining access. Lastly, an independent steering group of researchers, practitioners, policy makers, and public members will be formed and a sub-committee from this group will act to review and approve access requests.

In addition to the developments noted above to improve the quality of The National Referral Database (capturing further details of ERS including specific exercise components, fidelity of interventions, inclusion of wait-list controls, evaluation of captured outcomes etc.), it is hoped that the database which will grow to incorporate new pathways and schemes outside of the traditional conceptualization of the ERS. Over time it is envisaged that the learnings of The National Referral Database will be incorporated into practice and policies locally, nationally, and globally and thus, as data is fed back into the database, will facilitate continued evaluation. As the introduction of novel schemes and approaches occurs their evaluation in comparison to established standards can be facilitated. In considering the widening interest in social prescribing (Department for Digital, Culture, Media, and Sport [DDCMS], 2018; NHS, 2019), linking with established networks of alterative referral pathways that fit within the realm of physical activity may also foster innovation in this space. We hope to be able to report on these advancements in future papers and reports in keeping with acknowledgment from NICE regarding our efforts (NICE, 2018), and for other researchers to involve themselves in utilizing The National Referral Database to better understand ERSs and other physical activity based interventions. We have begun to liaise directly with the wider community that we anticipate will utilise The National Referral Database including:

- Academics and researchers who have expressed interest in the existing data, in addition to plans to enhance the database, and who need to data in order to answer key research questions relating to this area.

- Policy makers and stakeholders from key organisations who have expressed interest in the resource and findings generated from it to inform strategy, policy, and investment in this area.

- Practitioners who work within this area who have expressed interest in the findings generated in order to help guide their practice.

Thus, at this time we wish to end with a call to those in the wider community who are interested in this area that we have not yet reached. The success of this endeavour relies upon the demand for the potential insight that such a resource as The National Referral Database might provide. Those who are delivering ERS or other physical activity related schemes should look to capture data and feed it into the database once its platform has been developed; researchers should look to engage with it to 
answer key research questions regarding these schemes; and policy makers and practitioners should utilize these insights to inform what they do.

\section{REFERENCES}

1. An, P., Rice, T., Gagnon, J., Borecki, I. B., Pérusse, L., Leon, A. S., Skinner, J. S., Wilmore, J. H., Bouchard, C., \& Rao, D. C., 1999. Familial aggregation of resting blood pressure and heart rate in a sedentary population: The heritage family study. Am J Hypertension, 12(3), 264-270

2. Atkinson, G., Batterham, A. M., 2015. Ture and false interindividual differences in the physiological response to an intervention. Exp Physiol, 100(6), 577-588

3. Baro, E., Degoul, S., Beuscart, R., and Chazard, E., 2015. Toward a literature-driven definition of big data in healthcare. BioMed Res Int, Article ID 639021, 9

4. Beedie, C., Mann, S., Jimenez, A., Kennedy, L., Lane, A. M., Domone, S., Wilson, S., and Whyte, G., 2016. Death by effectiveness: Exercise as medicine caught in the efficacy trap. Br J Sports Med, 50(6), 323-324

5. Bertotti, M., Frostrick, C., Hutt, P., Sohanpal, R., and Carnes, D., 2018. A realist evaluation of social prescribing: an exploration into the context and mechanisms underpinning a pathway linking primary care with the voluntary sector. Primary Health Care Research \& Development, 19(3), 232-245

6. Bickerdike, L., Booth, Al., Wilson, P. M., Farley, K., and Wright, K., 2017. Social prescribing: less rhetoric and more reality. A systematic review of the evidence. BMJ Open, 7(4), e013384

7. Blume, J. D., McGowan, L. D., Dupont, W. D., and Greevy Jr, R. A., 2018. Second-generation $p$-values:
Improved rigor, reproducibiity, \& transparency in statistical analyses. PLoS ONE, 13(3), e0188299

8. Borrelli, B., 2011. The assessment, monitoring, and enhancement of treatment fidelity in public health clinical trials. J Public Health Dent, 71(S1), S52-S63

9. Buckley, B. J. R., Thijssen, D. H. J., Murphy, R. C., Graves, L. E. F., Whyte, G., Gillison, F. B., Crone, D., Wilson, P. M., \& Watson, P. M., 2018. Making a move in exercise referral: Co-development of a physical activity referral scheme. $J$ Public Health, Epub ahead of print

10. Caldwell, A., Vigotsky, A. D., Nuckols, G., Boardley, I., Schmidt, J., Tenan, M., ... Halperin, I., 2019. Moving sport and exercise science forward: A call for the adoption of more transparent research practices. Pre-print available at SportR $\chi i v$ : https://doi.org/10.31236/osf.io/fxe7 a

11. Chen, Y., Wu, J., Haschler, I., Majeed, A., Chen, T., and Wetter, T., 2011. Academic impact of a public electronic health database: Biobliometric analysis of studies using thegeneral practice research database. PLoS ONE, 6(6), e21404

12. Coote, J. H., \& Joyner, M. J., 2015. Is precision medicine the route to a healthy world? Lancet, 385(9978), P1617

13. Craig, C. L., Marshall, A. L., Sjöström, M., Bauman, A. E., Booth, M. L., Ainsworth, B. E., Pratt, M., Ekelund, U., Yngve, A., Sallis, J. F., and Oja, P., 2003. International physical activity questionnaire: 12country reliability and validty. Med Sci Sports Exerc, 35(8), 1381-1395

14. DDCMS, 2018. A connected society: A stratgegy for tackling loneliness - laying the foudnations for change. London: HM Government. https://assets.publishing.service.gov 
.uk/government/uploads/system/upl oads/attachment_data/file/750909/6. 4882_DCMS_Loneliness_Strategy_ web_Update.pdf

15. Duda, J., Williams, G., Ntoumanis, N., Daley, A., Eves, F., Mutrie, N., Rouse, P., Lodhia, R., Blamey, R., \& Jolly, K., 2014. Effects of a standard provision versus an autonomy supportive exercise referral programme on physical activity, quality of life and well-being indicators: a cluster randomised controlled trial. International Journal of Behavioral Nutrition and Physical Activity, 11(10).

16. Dugdill, L., Graham, R. C. \& McNair, F., 2005. Exercise referral: the public health panacea for physical activity promotion? a critical perspective of exercise referral schemes; their development and evaluation.. Ergonomics, Volume 48, pp. 1390-1410.

17. Geeta, A., Jamaiyah, H., Safiza, M. N., Khor, G. L., Kee, C. C., Ahmad, A. Z., Suzana, S., Rahmah, R., \& Faudzi, A., 2009. Reliability, technical errors of measurements and validity of intrusments for nutirional status assessment of adutls in Malaysia. Singapore Med $J, 50(10), 1013-1018$

18. Hawkins, J., Edwards, M., Charles, J., Jago, R., Kelson, M., Morgan, K., Murphy, S., Oliver, E., Simpson, S., Edwards, R. .T., \& Moore, G., 2017. Protocol for a feasibility randomised controlled trial of the use of Physical Activity monitors in an Exercise Referral Setting: The PACERS study. Pilot Feasibiliity Stud, 3, 51

19. Henderson, H. E., Evans, A. B., Allen-Collinson, J., \& Siriwardena, N. A., 2018. The 'wild and wooly' world of exercise referral schemes: contested interpretations of an exercise as medicine programme. Qual Res Sport Exerc Health, 10, 4
20. Hilton, C., Trigg, R., \& Minniti, A., 2015. Improving the psychological evaluation of exercise referral: Psychometric properties of the Exercise Referral Quality of Life Scale. Health Psychol Open, 7(2), 112

21. Husk, K., Blockley, K., Lovell, R., Bethel, A., Bloomfield, D., Warber, S., Pearson, M., Lang, I., Byng, R., and Garside, R., 2016. What appraoches to social prescribing work, for whom, and in what circumstances? A protocol for a realist review. Systematic Reviews, 5,93

22. King, N. A., Hopkins, M., Caudwell, P., Stubbs, R. J., \& Blundell, J. E., 2008. Individual variability following 12 weeks of supervised exercise: identification and characterization of compensation for exercise-induced weight loss. Int $J$ Obesity, 32, 177-184

23. Kroll, T., Kehn, M., Ho, P., \& Groah, S., 2007. The SCI Exercise Self-Efficacy Scale (ESES): development and psychmetric properties. Int J Behav Nutr Phys Act, 4, 34

24. Lee, P. H., Macfarlane, D. J., Lam, T. H., and Stewart, S. M., 2011. Validity of the International Physical Activity Questionnaire Short Form (IPAQ-SF): a systematic review. Int J Behav Nutr Phys Act, 8, 115

25. Leff, D. R., and Yang, G., 2015. Big data for precision medicine. Engineering, 1(3), 277-279

26. Martin-Borràs, C., Giné-Garriga, M., Puig-Ribera, A., Martin, C., Solà , M., \& Cuesta-Vargas, A. I., 2018. A new model of exercise referral scheme in primary care: is the effect on adherence to phsyical activity sustainable in the long term? A 15month randomised controlled trial. BMJ Open, 8, e017211 
27. Moffat, S., Steer, S., Lawson, S., Penn, L., and O'Brien, N., 2017. Link Worker social prescribing to improve health and well-being for people with long-term conditions: qualitative study of service used perceptions. BMJ Open, 7(7), e015203

28. NHS, 2019. The NHS Long Term Plan. London: NHS. https://www.longtermplan.nhs.uk/p ublication/nhs-long-term-plan/

29. NICE, 2014. Physical activity: exercise referral schemes (PH54), London: NICE.

30. NICE, 2018. Physical activity: exercise referral schemes (PH54), London: NICE.

https://www.nice.org.uk/guidance/p h54/resources/physical-activityexercise-referral-schemes-pdf1996418406085

31. Orrow, G., Kinmonth, A.-L. A.-L., Sanderson, S., \& Sutton, S., 2012. Effectiveness of physical activity promotion based in primary care: systematic review and meta-analysis of randomised controlled trials. BMJ (Clinical Research Ed.), 344(mar26 1), e1389.

32. Pavey, T. G., Fox, K., Hillsdon, M., Anokye, N., Campbell, J., Foster, C., Green, C., Moxham, T., Mutrie, N., Searle, J., Trueman, P., \& Taylor, R., 2011. Effect of exercise referral schemes in primary care on physical activity and improving health outcomes: systematic review and meta-analysis. British Medical Journal, Volume 343.

33. Pickering, T. G., Hall, J. E., Appel, L. J., Falkner, B. E., Graves, J., Hill, M. N., Jones, D. W., Kurtz, T., Sheps, S. G., \& Roccella, E J., 2005. Recommendations for blood pressure measurment in humans and experimental animals. Part 1: Blood pressure measurement in humans: A statement for professionals from the subcommittee of profressional and public education of the American Heart Association Council on high blood pressure research. Circulation, 111, 697-716

34. Raghupathi, W., and Raghupathi, V., 2014. Big data analytics in healthcare: promise and potential. Health Inf Sci Syst, 2, 3

35. Roundtable on Value and ScienceDriven Health Care; Forum on Drug Discovery, Development, and Translation; Board on Health Sciences Policy; Institute of Medicine. Large Simple Trials and Knowledge Generation in a Learning Health System: Workshop Summary. Washington (DC): National Academies Press (US); 2013 Dec 5. 2, Large Simple Trials Now and Looking Forward. Available from: https://www.ncbi.nlm.nih.gov/book s/NBK201271/

36. Rowley, N., Mann, S., Steele, J., Horton, E., \& Jimenez, A., 2018. The effects of exercise referral schemes in the united kingdom in those with cardiovascular, mental health, and musculoskeletal disorders: An updated systematic review. In press

37. Rowley, N., Steele, J., Wade, M., Copeland, R., Mann, S., Horton, E., and Jimenez, A., 2019. Are exercise referral schemes effective in increasing physical activity levels? Observational findings using individual patient data meta-analysis from The National Referral Database Pre-print available at SportRxiv: 10.31236/osf.io/ckdwn

38. Slade, S. C., Dionne, C. E., Underwood, M., Buchbinder, R., Beck, B., Bennell, K., Brosseau, L., Costa, L., Cramp, F., Feehan, E. C. L., Ferreira, M., Forbes, S., Glasziou, P., Habets, B., Harris, S., Hay-Smith, J., Hillier, S., Hinman, R., Holland, A., Hondras, M., Kelly, G., Kent, P., Lauret, GJ., Long, A., 
Maher, C., Morso, L., Osteras, N., Peterson, T., Quinlivan, R., Rees, K., Regnauz, JP., Rietberg, M., Saunders, D., Skoetz, N., Sogaard, K., Takken, T., van Tulder, M., Voet, N., Ward, L., and White, C., 2016. Consensus on Exercise Reporting Template (CERT): Modified delphi study. Physical Therapy, 96(10), pp 1514-1524

39. Stewart-Brown, S., Tennant, A., Tennant, R., Platt, S., Parkinson, J., \& Welch, S., 2009. Internal construct validity of the WarwickEdinburgh Mental Wellbeing Scale (WEMWBS): a Rasch analysis using data from the Scottish Health Education Population Survey. Health Wual Life Outcomes, 7, 15

40. Topp, C. W., Østergaard, S. D., Søndergaard, S., \& Bech, P., 2015. The WHO-5 well-being index: A systematic review of the literature. Psychotherapy and Psychosomatics, 84, 167-176

41. Van den Broeck, J., Cunningham, S. A., Eeckels, R., and Herbst, K., 2005. Data cleaning: Detecting, diagnosing, and editing data abnormalities. PLoS Medicine, 2(10), pp e267

42. Wade, M., Mann, S., Copeland, R., Batterham, A., and Steele, J., 2019. The effect of exercise referral schemes upon health and wellbeing: Initial observational insights using individual patient data meta-analysis from The National ReferrAll Database. Pre-print available at SportRqiv: 10.31236/osf.io/yebmr

43. Winett, R. A., Davy, B. M., Savla, J., Marinik, E. L., Winett, S. G., Baugh, M. E., \& Flack, K. D., 2014. Using response variation to develop more effective personalized behavioural medicine?: evidence from the Resist Diabetes study. Transl Behav Med, 4(3), 333-338 